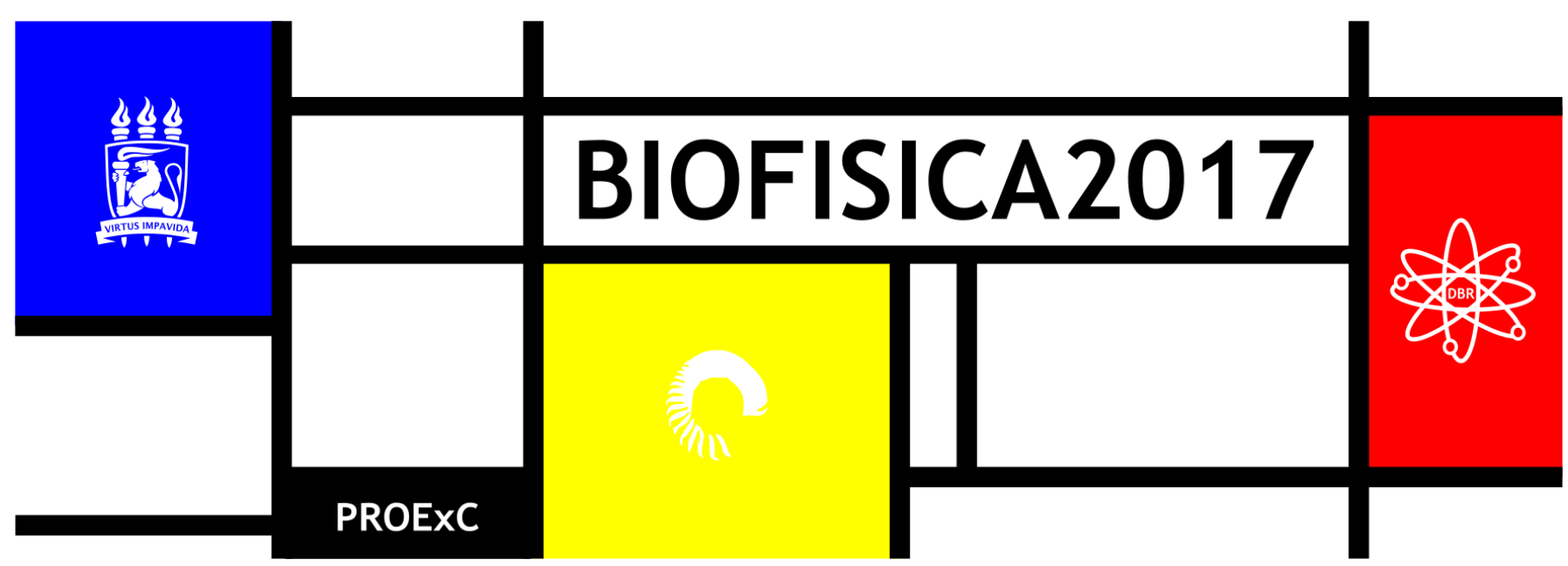

\title{
RELEVÂNCIA DOS SEDIMENTOS EM SUSPENSÃO PARA A DISTRIBUIÇÃO DE ELEMENTOS QUÍMICOS NO RIO BEBERIBE
}

\author{
Denilson Lyra*, Rafaela Matos, Elvis França. \\ Centro Regional de Ciências Nucleares do Nordeste, CRCN/NE. \\ *denilson.lyra@ufpe.br
}

\section{INTRODUÇÃO}

Quantidades expressivas de elementos químicos nos rios urbanos são liberadas por atividades antropogênicas e transportadas por grandes distâncias como material particulado em suspensão (OLLIVIER et al., 2011). A sedimentação é favorecida em manguezais, pois a vegetação atua como barreira natural contra as ações das marés, aumentando o armazenamento de material particulado (ADAME et al, 2010). Sendo assim, estudos utilizando sedimentos em suspensão são extremamente necessários para a avaliação de impactos ambientais em ecossistemas aquáticos.

A metodologia da coleta é muito importante para a análise química de sedimentos em suspensão. A quantidade de sedimentos amostrados, a época de coleta e a ocorrência de eventos extremos (alta precipitação) podem contribuir significativamente para as frações de massa dos elementos químicos. França et al. (2010), por exemplo, encontraram composição química bastante variável para coleta de sedimentos em suspensão em diferentes pontos nas áreas urbanas e rurais do Rio Piracicaba.

Este trabalho tem como objetivo quantificar $\mathrm{Al}, \mathrm{Br}, \mathrm{Ca}, \mathrm{Fe}, \mathrm{K}, \mathrm{Mn}$, $\mathrm{Ni}, \mathrm{Pb}, \mathrm{Si}, \mathrm{Sr}$, Ti e $\mathrm{Zn}$ no sedimento em suspensão do Rio Beberibe e demonstrar sua relevância para a distribuição de elementos químicos.

\section{MATERIAL E MÉTODOS}

Foram coletadas oito amostras compostas de aproximadamente 20 litros de água no Rio Beberibe (Olinda-PE), trecho próximo ao Parque Memorial Arcoverde, ao longo de 105 minutos (15 minutos cada) em um evento de chuva.

Após seis meses de sedimentação espontânea em galões vedados de plástico de 20 litros sob baixa temperatura $\left(4^{\circ} \mathrm{C}\right)$, a água sobrenadante foi removida por sucção (Figura 1-A), o material restante (Figura 1-B) foi processado em centrífuga Excelsa II da Fanem (Figura 1-C) para a obtenção dos sedimentos em suspensão (Figura 1-D).

Com auxílio de seringa, o sobrenadante foi cuidadosamente retirado. 0 particulado sólido foi submetido à secagem a frio por 48 horas (Figura 1-E). Com isso, obteve-se material suficiente (em torno de $0,5 \mathrm{~g}$ ) para a preparação das amostras para a análise por
EDXRF (Figura 1-F). Enquanto os detalhes do procedimento analítico de obtenção do particulado em suspensão podem ser consultados em Lyra (2016).

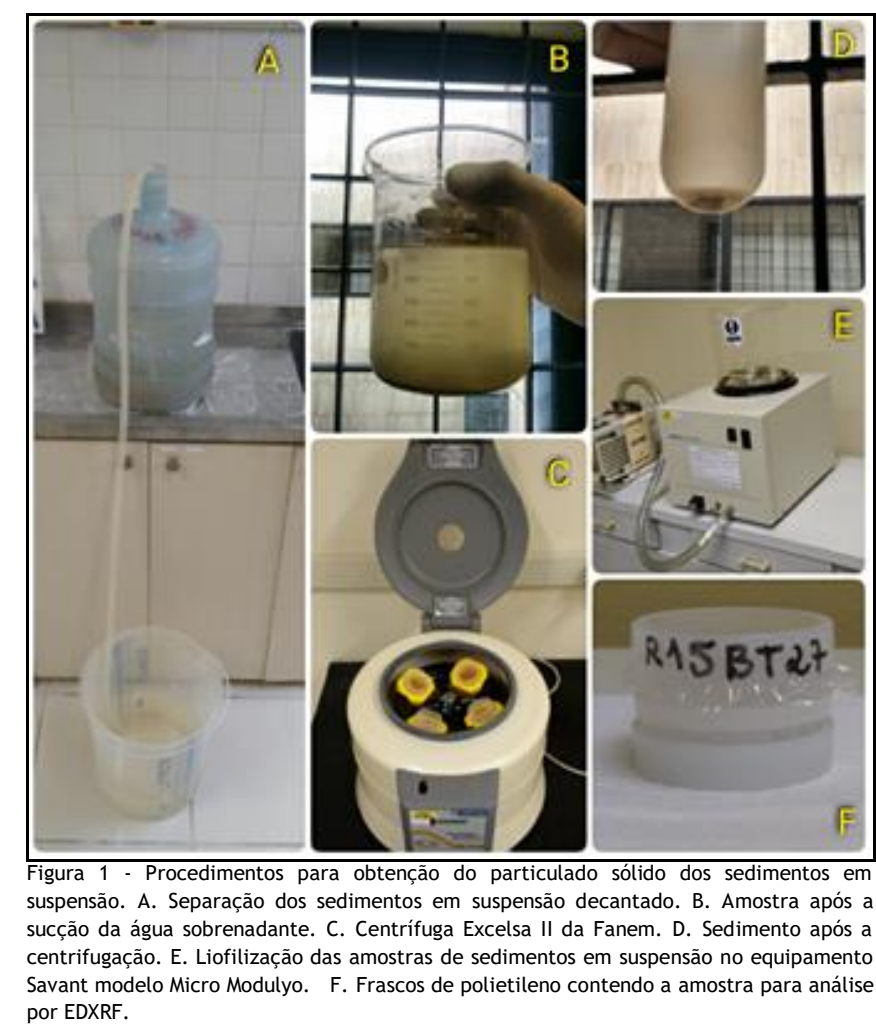

\section{RESULTADOS E DISCUSSÃO}

Na Figura 2 estão ilustradas as concentrações de sedimentos em suspensão para cada amostra coletada às margens do Rio Beberibe. A concentração média do particulado sólido em suspensão de 157 
$\mathrm{mg} \mathrm{L}^{-1}$ foi superior à média de ecossistemas estuarinos australianos (117 $\mathrm{mg} \mathrm{L}^{-1}$ ) estudados por Adame et al. (2010). A segunda amostra com tempo de $15 \mathrm{~min}$ apresentou maior concentração de particulado em suspensão ( $347 \mathrm{mg} \mathrm{L}^{-1}$ ). Após 30 minutos de coleta, as concentrações dos sedimentos em suspensão estabilizaram-se em cerca de $100 \mathrm{mg} \mathrm{L}^{-1}$.

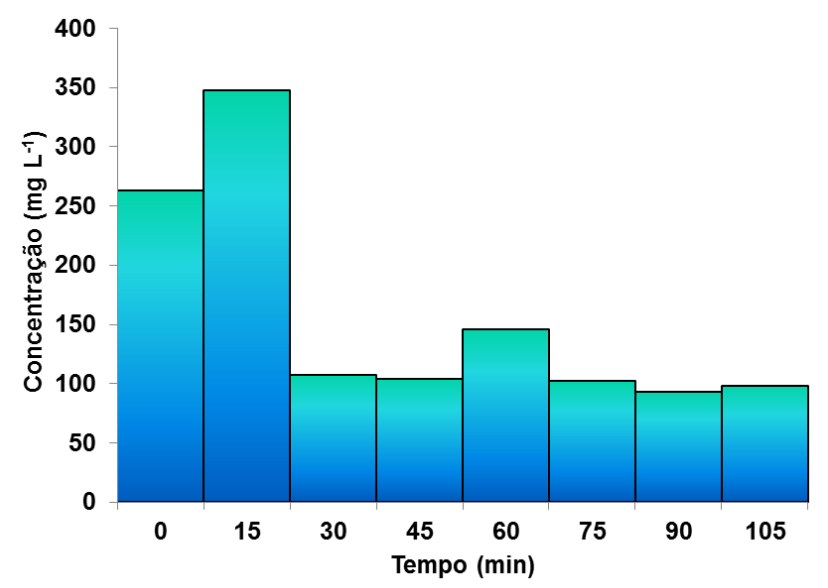

Figura 2 - Concentração total de sedimentos em suspensão $\left(\mathrm{mg} \mathrm{L}^{-1}\right)$ do Rio Beberibe quantificados ao longo de 105 minutos.

A Tabela 1 mostra os valores médios das concentrações dos elementos químicos $\mathrm{Al}, \mathrm{Br}, \mathrm{Ca}, \mathrm{Fe}, \mathrm{K}, \mathrm{Mn}, \mathrm{Ni}, \mathrm{Pb}, \mathrm{Si}, \mathrm{Sr}$, Ti e $\mathrm{Zn}$ quantificados nos sedimentos em suspensão do Rio Beberibe.

Tabela 1 - Frações de massa $\left(\mathrm{mg} \mathrm{kg}^{-1}\right)$ dos elementos químicos quantificados nos sedimentos em suspensão do Rio Beberibe.

\begin{tabular}{cccc}
\hline $\begin{array}{c}\text { Elementos } \\
\text { químicos }\end{array}$ & $\begin{array}{c}\text { Concentração }\left(\mathbf{m g ~ k g}^{-1}\right) \\
\text { Média }\end{array}$ & Max $\left(\mathbf{m g ~ k g}^{-1}\right)$ & Min $\left(\mathbf{m g ~ k g}^{-1}\right)$ \\
\hline $\mathrm{Al}$ & 137.000 & 144.000 & 130.000 \\
$\mathrm{Br}$ & 31 & 37 & 26 \\
$\mathrm{Ca}$ & 7.890 & 8.770 & 6.400 \\
$\mathrm{Fe}$ & 55.100 & 56.700 & 51.200 \\
$\mathrm{~K}$ & 5.000 & 5.920 & 4.530 \\
$\mathrm{Mn}$ & 553 & 676 & 358 \\
$\mathrm{Ni}$ & 26 & 28 & 23 \\
$\mathrm{~Pb}$ & 100 & 108 & 94 \\
$\mathrm{Si}$ & 158.000 & 163.000 & 153.000 \\
$\mathrm{Sr}$ & 154 & 166 & 143 \\
$\mathrm{Ti}$ & 6.600 & 6.800 & 6.500 \\
$\mathrm{Zn}$ & 247 & 318 & 212 \\
\hline
\end{tabular}

\section{CONCLUSÕES}

Quantidades expressivas de elementos químicos foram transportados pelos sedimentos em suspensão até a foz do Rio Beberibe. Os resultados enfatizam a necessidade de contínua monitoração dos ecossistemas aquáticos, principalmente em ambiente urbano.

\section{REFERÊNCIAS}

ADAME, M. F.; NEIL, D.; WRIGHT, S. F.; LOVELOCK, C. E. Sedimentation within and among mangrove forests along a gradient of geomorphological settings. Estuarine, Coastal and Shelf Science, v. 86, p. 21-30, 2010.

FRANÇA, E. J.; FERNANDES, E. A. N.; CAVALCA, I. P. O.; FONSECA, F. Y.; CAMILLI, L.; RODRIGUES, V. S.; BARDINI JUNIOR,; FERREIRA, C.; J. R.; BACCHI, M. A. Characterizing suspended sediments from the Piracicaba River Basin by means of $k_{0}$ - INAA. Nuclear Instruments and Methods in Physics Research A, v. 622, p. 479483, 2010.

LYRA, D. T. Determinação de elementos químicos de solos e sedimentos em suspensão para monitoração da qualidade ambiental de manguezal de Pernambuco. Universidade Federal de Pernambuco. Dissertação (Mestrado). Tecnologias Energéticas e Nucleares. 2016, 98 p.

OLLIVIER, P.; RADAKOVITCH, O.; HAMELIN, B. Major and trace element partition and fluxes in the Rhône River. Chemical Geology, v. 285, p. 15-31, 2011. 